\title{
Statin prescription among patients with type 2 diabetes in Botswana: findings and implications
}

\author{
Julius Chacha Mwita ${ }^{1,2^{*}}$ (D), Brian Godman $3,4,5$ and Tonya M. Esterhuizen ${ }^{2}$
}

\begin{abstract}
Background: There is evidence of statin benefit among patients with diabetes regardless of cholesterol levels or prior cardiovascular disease history. Despite the evidence, there is under-prescription of statins in clinical practice. This study aimed to assess statin prescriptions and associated factors among patients with type 2 diabetes in Botswana.

Methods: The study was a secondary data analysis of 500 randomly selected type 2 diabetes patients at a specialised diabetes clinic at Gaborone, Botswana. We assessed the proportion of statin-eligible patients who are prescribed statins and evaluated the adjusted associations between various factors and statin prescriptions.

Results: Overall, 477 (95.4\%) participants were eligible for a statin prescription. Clinicians prescribed statins in 217 (45.5\%) of eligible participants, and only one (4.4\%) ineligible participant. The probability of a statin prescription was higher in participants with high baseline low-density lipoprotein cholesterol (risk ratio [RR]: 1.49; 95\%Cl: 1.17-1.89), increasing duration of diabetes (RR: 1.01; 95\% Cl 1.00-1.03) and the presence of chronic kidney disease (RR: 1.35; 95\%Cl: 1.06-1.74).

Conclusion: A large proportion with type 2 diabetes in Gaborone is not receiving statins. Clinicians did not consider most guideline-recommended indications for statin prescriptions. The findings call for improvement in diabetes quality of care by implementing evidence-based guideline recommendations.
\end{abstract}

Keywords: Statin, Type 2 diabetes mellitus, Prescription and Botswana

\section{Background}

Cardiovascular disease (CVD), which includes coronary artery disease (CAD), cerebrovascular accident (CVA), and peripheral arterial disease (PAD), is common and contributes to over two-thirds of mortality among patients with type 2 diabetes mellitus [1-3]. While the presence of type 2 diabetes alone confers the highest risk

\footnotetext{
* Correspondence: mwitajc@ub.ac.bw

${ }^{1}$ Department of Internal Medicine, Faculty of Medicine, University of Botswana, Private Bag, 00713 Gaborone, Botswana

${ }^{2}$ Division of Epidemiology and Biostatistics, Department of Global Health,

Faculty of Medicine and Health Sciences, Stellenbosch University, Stellenbosch, South Africa

Full list of author information is available at the end of the article
}

for CVD of any single risk factor, the coexistence of other cardiovascular risk factors is a common phenomenon [3, 4]. Consequently, guidelines advise screening and optimal treatment of CVD risk factors in patients with diabetes $[5,6]$. Besides, prescribing of 3hydroxy-3-methylglutaryl-coenzyme A reductase inhibitors (statins) among patients with type 2 diabetes reduces the risk of major CVD events by $23-33 \%$ [7-9]. There is evidence of statin benefit among patients with diabetes regardless of their low-density lipoprotein cholesterol (LDL-C) values or prior CVD history [7, 9-14]. For each $\mathrm{mmol} / \mathrm{l}$ reduction in LDL-C, there is evidence of a $9 \%$ relative reduction in all-cause mortality in

C C The Author(s). 2020 Open Access This article is licensed under a Creative Commons Attribution 4.0 International License, which permits use, sharing, adaptation, distribution and reproduction in any medium or format, as long as you give appropriate credit to the original author(s) and the source, provide a link to the Creative Commons licence, and indicate if changes were made. The images or other third party material in this article are included in the article's Creative Commons licence, unless indicated otherwise in a credit line to the material. If material is not included in the article's Creative Commons licence and your intended use is not permitted by statutory regulation or exceeds the permitted use, you will need to obtain permission directly from the copyright holder. To view a copy of this licence, visit http://creativecommons.org/licenses/by/4.0/. The Creative Commons Public Domain Dedication waiver (http://creativecommons.org/publicdomain/zero/1.0/) applies to the data made available in this article, unless otherwise stated in a credit line to the data. 
patients with diabetes [15]. Irrespective of LDL-C, guidelines recommend statins for patients with diabetes aged $\geq 40$ years without atherosclerotic cardiovascular disease (ASCVD), or those who are younger than 40 years but with existing ASCVD or additional risk factors [5, 6].

While some studies in developed countries have reported high use of statins among patients with type 2 diabetes, there has generally been under-prescribing of statins across many countries [16-18]. Statin prescribing among patients with type 2 diabetes is as high as $100 \%$ in developed countries but as low as $3-13 \%$ in Africa [17-23]. The suboptimal utilisation of statin therapy in Africa is due to many factors, but mainly limited access to standard diabetes care because of the high cost of tests and medications with typically high co-payment levels [22]. Affordability is a critical issue in several African countries where there is no universal healthcare, with the cost of medicines accounting for up to $70 \%$ of total healthcare expenditure, much of which is out-ofpocket $[24,25]$. Statin under-prescribing is a concern given the high growth rates of cardiovascular diseases in sub-Saharan African countries and current poor control of cardiovascular diseases [26-31]. The underuse of statins significantly increases the incidence of cardiovascular events and associated mortality [32]. Although healthcare is free in Botswana, factors not related to cost may still affect the uptake of statins in patients with diabetes. This is problematic given current prevalence rates of diabetes in Botswana and the resultant impact on morbidity and mortality [33-35]. Published data on the impact of diabetes mellitus on CVD in Botswana are scant. About a quarter of patients admitted with heart failure had type 2 diabetes in a recent study in Gaborone [33]. Although data on atherosclerotic diseases in Botswana are missing, we can expect that diabetesrelated coronary atherosclerosis underlines some cases of heart failure [33, 35]. In addition, the rising burden and suboptimal control of CVD risk factors in patients with type 2 diabetes have become an increasing concern in Botswana [36]. One of the critical steps that will prevent or slow ASCVD in this suboptimally-treated patients is the use of statins [5]. Currently, there is no study assessing the extent of statin prescriptions among patients with type 2 diabetes in Botswana. We aimed to address this by evaluating the extent of statin prescription among patients with type 2 diabetes in Botswana. Our secondary aim was to determine factors associated with statin prescription among type 2 diabetes.

\section{Methods}

\section{Study design}

We conducted a secondary analysis of data from a previous study among type 2 diabetics at a specialised diabetes clinic in Gaborone, Botswana. Any concerns with the management of diabetic patients in this dedicated clinic are likely to be exacerbated in non-specialist centres such as primary healthcare centres.

\section{Participant recruitment and data collection}

The original study took place between August 2017 and February 2018 [36]. The primary objective of the original study was to assess glycaemic, low-density lipoprotein, and hypertension control in patients with type 2 diabetes. The study included 500 randomly selected patients with type 2 diabetes aged $\geq 18$ years, attending the clinic for at least 3 months before data collection. Using systematic random sampling, we enrolled every eighth patient from the daily lists of patients attending the clinic. The enrolment occurred in the mornings and afternoons until either the daily target of ten patients was achieved or the end of clinic consultations. Demographic data (age, sex, occupation, educational attainment, and marital status), duration of diabetes, and the type of diabetes medications were collected. Other information was the history of hypertension, lipid disorders, ischemic heart diseases, stroke or peripheral vascular disease. We also recorded data on the use of medications for hypertension and lipid disorders (including statins), and anthropometric measurements (weight, height, hip and waist circumferences). With participants in light clothing and without footwear, we measured participants' height and weight to the nearest $0.1 \mathrm{~cm}(\mathrm{~cm})$ and $0.1 \mathrm{~kg}(\mathrm{~kg})$ respectively [37]. We also measured the hip and waist circumferences (to the nearest $0.1 \mathrm{~cm}$ a non-stretchable tape measure at a hip and level midway between the lowest rib and iliac crest [38]. After $10 \mathrm{~min}$ of rest, three seated blood pressure (BP) measurements were taken from the right arm using a digital automatic BP monitor (Omron) [37, 39]. We documented the average of the three readings and that of each patient's previous visit. In addition, we used the electronic medical records to obtain participants' serum creatinine and low-density lipoprotein-cholesterol (LDL-C), and urine dipsticks for proteinuria results within 6 months of enrolment [36]. The diabetes clinic has a satellite laboratory that performs tests per protocol as defined by the ISO-9000 certified Princess Marina Hospital clinical laboratory. Total cholesterol (TC), triglycerides (TG) and high-density lipoprotein cholesterol (HDL-C) are measured enzymatically in plasma using commercial kits made by Roche Diagnostics, Switzerland. LDL-cholesterol was calculated using the Friedwald formula as TC-HDL-C-TG/2.2 in $\mathrm{mmol} / \mathrm{dL}$ [40]. For the present study, we evaluated the extent of statin prescriptions among the participants. The primary outcome measure was receiving a statin prescription among statin-eligible participants. We assessed statin eligibility based on the Society for Endocrinology, Metabolism, and Diabetes of South Africa 
(SEMDSA) guidelines [6]. According to SEMDSA, the eligibility for statin prescribing included any CVD or chronic kidney disease (CKD), age above 40 years, and diabetes duration longer than ten years. In addition, a statin prescription is indicated in the presence of one or more of the following cardiovascular risk factors; hypertension, cigarette smoker, HDL-C level, family history of early $\mathrm{CAD}$, and any albuminuria [6]. Other independent variables included baseline serum LDL-C, body mass index (BMI), waist-hip ratio (WHR) and level of education.

\section{Definition of terms}

The diagnosis of hypertension based on the self-reported history of hypertension, the use of hypertensionlowering medications or sustained blood pressure $\geq 140$ / $90 \mathrm{mmHg}$ in more than one visit [41]. We defined CVD as the history of CAD, CVA (ischemic stroke, transient ischemic attacks), or PAD [6]. CAD was any documented definite or probable myocardial infarction, CAD-related revascularisation (surgery, angioplasty, stenting, or any combination of these), or stable angina in participants' medical records [42]. Data on CVA and PDA were extracted from participants' medical records as defined by the treating physician. Smoking status was a documented self-report of current smoking habits. We estimated glomerular filtration rate (eGFR) using the Modification of Diet in Renal Disease(MDRD), and classified patients with eGFR $<60 \mathrm{ml} /$ minute $/ 1.73 \mathrm{~m}^{2}$ as having CKD [43]. BMI was categorized into underweight for BMI $<18.5 \mathrm{~kg} / \mathrm{m}^{2}$; normal for BMI of $18.5-24.9 \mathrm{~kg} / \mathrm{m}^{2}$, overweight for $25.0-29.9 \mathrm{~kg} / \mathrm{m}^{2}$; or obese for BMI $\geq 30$ $\mathrm{kg} / \mathrm{m}^{2}$ [44]. We also calculated the WHR by dividing waist circumference $(\mathrm{cm})$ by hip circumference $(\mathrm{cm})$ and defined WHR $\geq 0.85$ for women and $\geq 0.90$ for men as high [38]. Dipstick proteinuria appeared as negative (-), trace, $(+),(++)$, or $(+++)$ in the dataset. We classified proteinuria in individuals with $\geq(+)$ dipstick proteinuria results. For patients already on lipid-lowering medications and whose baseline 'untreated' levels of lipid profile were not available, we estimated the LDL-C levels before the initiation of statin treatment as in previous studies [45]. The adjustment was made based on the assumption that most patients received atorvastatin (the only statin available in the public sector in Botswana) at a dosage of at least $10 \mathrm{mg}$ per day and an overall adherence of $60 \%$ [46]. We calculated the baseline LDL-C levels by assuming that the measured LDL-C is a result of a $25 \%$ reduction from baseline [45]. Baseline LDL-C levels above $4.13 \mathrm{mmol} / \mathrm{l}$ were considered high [47].

\section{Statistical analysis}

Clean data were imported from MS Excel and analysed using Stata Version 14 (Stata Corp, College Station, TX).
Categorical variables were presented as frequencies and percentages, and continuous variables as mean (standard deviation [SD]) or medians [first-third quartiles]. Comparison of clinical and demographic factors by gender and statin use was achieved by using the Chi-square or Fisher's exact tests for categorical variables, and independent student's t-tests or Wilcoxon rank-sum test for continuous variables as appropriate. A 2 -sided $p$-value $<0.05$ was considered as statistically significant. As the outcome of interest (a statin prescription) was a common event, and our study design was cross-sectional, we estimated relative risks (RRs) as measures of association. Log-binomial models or generalised linear models for the binomial family were fitted to assess for independent predictors for statin prescribing. The multivariable model included all factors with $p<0.2$ on bivariate analysis. We used a backward selection modelling method with probabilities set at 0.05 and 0.1 for inclusion and exclusion; respectively. We report adjusted risk ratios (RRs), 95\% confidence intervals (CIs), and $p$-values. With a sample size of 477 statineligible participants, we were able to estimate the prevalence of statin use of $13 \%$ with a margin of error of $3 \%$ on a two-sided alpha level of 0.05 [22].

\section{Results}

There were 500 participants in the dataset, with a mean (SD) age of 58.9 (12.2) years and 330 (66\%) were females. Table 1 summarises baseline participants' characteristics by gender. The majority (96.7\%) of participants aged $\geq 40$ years and women were significantly older than men. Approximately a third (34.4\%) of participants had a diabetes duration of over ten years. Hypertension (84.7\%) and obesity (51.6\%) were prevalent, especially in female participants. Overall, CKD (11.3\%), proteinuria $(10.7 \%)$, CVD (8.8\%), and smoking (3.4\%) were uncommon. The mean (SD) baseline LDL-C was 3.1 (1.2) $\mathrm{mmol} / \mathrm{L}$, and significantly higher in female than male participants.

\section{Statin eligibility and prescribing rates}

Of the 500 participants, 477 (95.4\%) were eligible for a statin prescription. Clinicians prescribed statins (exclusively atorvastatin) in 217 (45.5\%) of statin-eligible participants, and only one (4.4\%) ineligible participant. Seven (1.5\%) participants received prescriptions of other lipid-lowering medications alone or in combination with statins. Of those who were eligible for statins, statinprescribed individuals differed from those without prescriptions in several parameters on the bivariate analysis (Table 2). Relative to the statin-non-prescribed group, the statin-prescribed group had a longer duration of diabetes $(8.9$ years vs. 6.0 years; $p<0.001)$; were older $(61.5$ years vs 59.2 years; $p=0.018$ ), more likely to be hypertensive $(85.7 \%$ vs $78.1 \% ; p<0.032)$, more likely to have 
Table 1 Demographic and clinical characteristics of patients with type 2 diabetes at a specialised Diabetes clinic in Gaborone $(N=477)$

\begin{tabular}{|c|c|c|c|}
\hline Characteristics & All $(N=477)$ & Males $(n=160)$ & Females $(n=317)$ \\
\hline Age, mean(SD), years & $60.3(10.8)$ & $56.8(11.5)$ & $62.0(10.1)$ \\
\hline Age $>40$ years $n(\%)$ & 461(96.7) & 150(93.8) & $311(98.1)$ \\
\hline Diabetes duration, median, IQR, years & $7(3-13)$ & $8.9(3-14)$ & $7(3-13)$ \\
\hline Diabetes duration > 10 years $n(\%)$ & $164(34.4)$ & 63(39.4) & 101(31.9) \\
\hline BMI, mean (SD) kg/m ${ }^{2}$ & $30.7(6.0)$ & $29.0(5.2)$ & $31.6(6.1)$ \\
\hline Normal weight n(\%) & $85(17.8)$ & $39(24.4)$ & $46(14.5)$ \\
\hline Overweight n(\%) & 146(30.6) & $59(36.7)$ & $87(27.4)$ \\
\hline Obese n(\%) & $246(51.6)$ & $62(38.8)$ & 184(58.0) \\
\hline \multicolumn{4}{|l|}{ Marital status } \\
\hline Living alone $\mathrm{n}(\%)$ & $247(51.8)$ & $47(29.4)$ & $200(63.1)$ \\
\hline Living with a partner n(\%) & 230(48.2) & 113(70.6) & 117(36.9) \\
\hline \multicolumn{4}{|l|}{ Education status } \\
\hline$\leq$ Primary education, $\mathrm{n}(\%)$ & $306(64.1)$ & $82(51.3)$ & 224(70.7) \\
\hline$\geq$ Secondary or tertiary, n(\%) & $171(35.9)$ & $78(48.7)$ & $93(29.3)$ \\
\hline WHR, mean (SD) & $0.94(0.10)$ & $0.97(0.08)$ & $0.93(0.09)$ \\
\hline Low WHR n (\%) & $79(16.6)$ & $67(41.9)$ & $12(3.8)$ \\
\hline High WHR n (\%) & 398(83.4) & 93(58.1) & $305(96.2)$ \\
\hline Hypertension n (\%) & $404(84.7)$ & 120(75.0) & 284(89.6) \\
\hline Use of antihypertensive $n$ (\%) & 389(81.6) & 110(68.8) & 279(88.0) \\
\hline Smoking n (\%) & $16(3.4)$ & $12(7.5)$ & $4(1.3)$ \\
\hline Lipid-lowering medications n (\%) & $224(47.0)$ & $70(43.8)$ & 154(48.6) \\
\hline Statins n (\%) & $217(45.5)$ & $68(42.5)$ & 149(47.0) \\
\hline Others n (\%) & $7(1.5)$ & $2(1.6)$ & $5(1.6)$ \\
\hline CVD n (\%) & $42(8.8)$ & $15(9.4)$ & $27(8.5)$ \\
\hline PAD n (\%) & $11(2.3)$ & $3(1.9)$ & $8(2.5)$ \\
\hline Coronary artery disease n (\%) & $12(2.5)$ & $5(3.3)$ & $7(2.2)$ \\
\hline Cerebrovascular disease n (\%) & $22(4.6)$ & $8(5.0)$ & $14(4.4)$ \\
\hline CKD n (\%) & $54(11.3)$ & 24(15.0) & $30(9.5)$ \\
\hline Proteinuria n (\%) & $51(10.7)$ & $27(16.9)$ & $24(7.6)$ \\
\hline HbA1c mean (SD), \% & $8.4(2.4)$ & $8.5(2.6)$ & $8.3(2.3)$ \\
\hline Baseline LDL-C, mean (SD), mmol/L & $3.1(1.2)$ & $2.8(1.1)$ & $3.3(1.2)$ \\
\hline Normal & $315(66.0)$ & 113(70.6) & $202(63.7)$ \\
\hline High & $59(12.4)$ & $9(5.6)$ & $50(15.8)$ \\
\hline Missing & 103(21.6) & $38(23.8)$ & $65(20.5)$ \\
\hline
\end{tabular}

Legend: BMI Body Mass Index, CKD chronic kidney disease, CVD cardiovascular disease, HbA1C Haemoglobin A1C, IQR interquartile range, LDL-C low-density lipoprotein cholesterol, $P A D$ peripheral artery disease, $S D$ standard deviation, WHR waist-hip ratio

CKD $(17.2 \%$ vs $6.6 \% ; p=0.001)$, and a higher baseline LDL-C ( 3.3 vs $2.9 \mathrm{mmol} / \mathrm{L} ; \mathrm{p}<0.001$ ). The two groups did not differ significantly in the presence of CVD, proteinuria and gender.

\section{Multivariable analysis}

The multivariable log-binomial model examined adjusted associations between statin prescription and various factors. The best fit had the following covariates: age, the duration of diabetes, BMI, hypertension, a high baseline LDL-C, CKD, CVD, and proteinuria. Increasing diabetes duration was associated with an increased likelihood (RR: 1.01; 95\%CI 1.00-1.03) of receiving a statin prescription (Table 3). The presence of CKD (RR: 1.35; 95\%CI: 1.06-1.74) and a high baseline LDL-C (RR: 1.49; 95\%CI: 1.17-1.89) were also associated with an increased likelihood of a statin prescription. Age, BMI, history of CVD, and a diagnosis of hypertension were not 
Table 2 Factors associated with statin prescription among statin-eligible patients with type 2 diabetes at a specialised Diabetes clinic in Gaborone $(N=477)$

\begin{tabular}{|c|c|c|c|}
\hline Characteristics & Statin not prescribed $(n=260)$ & Statin prescribed $(n=217)$ & $P$-value \\
\hline \multicolumn{4}{|l|}{ Sex } \\
\hline Males, n (\%) & $92(35.4)$ & $68(31.3)$ & 0.351 \\
\hline Female, n (\%) & 168(64.6) & 149(68.7) & \\
\hline Diabetes duration, median, IQR, years & $6(2-12)$ & $8.9(4-15)$ & $<0.001$ \\
\hline Duration $\leq 10$ years & 179(68.9) & 134(61.8) & 0.104 \\
\hline Diabetes duration $>10$ years & $81(31.1)$ & $83(38.2)$ & \\
\hline Age, mean (SD), years & $59.2(10.8)$ & $61.5(10.7)$ & 0.018 \\
\hline Age $\leq 40$ years, $n(\%)$ & $12(4.6)$ & $4(1.8)$ & $<0.094$ \\
\hline Age > 40 years $n(\%)$ & 248(95.4) & 213(98.2) & \\
\hline \multicolumn{4}{|l|}{ Marital status } \\
\hline Living alone n (\%) & 135(51.9) & 112(51.6) & 0.946 \\
\hline Living with a partner $\mathrm{n}(\%)$ & $125(48.1)$ & $105(48.4)$ & \\
\hline \multicolumn{4}{|l|}{ Education status } \\
\hline$\leq$ Primary education, $\mathrm{n}(\%)$ & 166(63.9) & $140(64.2)$ & 0.879 \\
\hline$\geq$ Secondary or tertiary, n (\%) & $94(36.1)$ & 77(35.8) & \\
\hline Hypertension n (\%) & 212(81.5) & $192(88.5)$ & 0.036 \\
\hline Antihypertensive use n (\%) & 203(78.1) & 186(85.7) & 0.032 \\
\hline Smoking & $13(5.0)$ & $3(1.4)$ & 0.029 \\
\hline CVD, n (\%) & $20(7.7)$ & $22(10.1)$ & 0.538 \\
\hline PAD, n (\%) & $7(2.7)$ & $4(1.8)$ & 0.625 \\
\hline Coronary artery disease n (\%) & $6(2.3)$ & $6(2.8)$ & 0.751 \\
\hline Cerebrovascular diseases n (\%) & $9(3.5)$ & $13(6.0)$ & 0.190 \\
\hline BMI, mean (SD) kg/m² & $30.3(5.7)$ & $31.2(6.2)$ & 0.113 \\
\hline Normal weight n (\%) & $50(19.2)$ & $35(16.1)$ & 0.669 \\
\hline Overweight n (\%) & $79(30.4)$ & $67(30.9)$ & \\
\hline Obese n (\%) & 135(47.9) & $115(52.8)$ & \\
\hline WHR, mean (SD) & $0.94(0.08)$ & $0.95(0.10)$ & 0.106 \\
\hline Low WHR n (\%) & $46(17.7)$ & $33(15.2)$ & 0.467 \\
\hline High WHR n (\%) & $214(82.3)$ & 184(84.8) & \\
\hline CKD, n (\%) & $20(7.7)$ & $34(15.7)$ & 0.006 \\
\hline Proteinuria, n (\%) & $30(11.5)$ & $21(9.7)$ & 0.512 \\
\hline HbA1c mean (SD), \% & $8.4(2.6)$ & $8.4(2.2)$ & 0.948 \\
\hline Baseline LDL-C mean (SD), mmol/L & 2.9(0.9) & $3.3(1.4)$ & 0.003 \\
\hline Normal & $177(68.1)$ & $120(55.3)$ & $<0.001$ \\
\hline High & $17(6.5)$ & $42(19.4)$ & \\
\hline Missing & $66(25.4)$ & $55(25.3)$ & \\
\hline
\end{tabular}

Legend: $B M I$ body mass index, $C K D$ chronic kidney disease, $C V D$ cardiovascular disease, HbA1C haemoglobin A1C, IQR interquartile range, $L D L-C$ low-density lipoprotein cholesterol, $P A D$ peripheral artery disease, $S D$ standard deviation, WHR waist-hip ratio

associated with statin prescribing after adjustment for the other variables in the model.

\section{Discussion}

Less than half of the statin-eligible patients with type 2 diabetes at a specialised diabetes clinic in Botswana received a statin prescription. A longer duration of diabetes, a higher baseline LDL-C and the presence of chronic kidney disease were independently associated with the tendency to prescribe statins.

The under-prescription of statins in this population is a concern since the use of statins appreciably reduces 
Table 3 Adjusted relative risks for associations between various factors and statin prescription among statin eligible patients with diabetes at a specialised diabetes clinic in Botswana

\begin{tabular}{llll}
\hline Characteristic & Risk ratio & 95\% Conf. Interval & $\boldsymbol{p}$-value \\
\hline Age, years & 1.006 & $0.994-1.017$ & 0.362 \\
CKD & 1.354 & $1.055-1.738$ & 0.017 \\
Hypertension & 1.336 & $0.846-2.110$ & 0.213 \\
$\mathrm{BMl}, \mathrm{kg} / \mathrm{m}^{2}$ & 1.014 & $0.994-1.034$ & 0.16 \\
High baseline LDL & 1.488 & $1.173-1.887$ & 0.001 \\
Diabetes duration, years & 1.014 & $1.000-1.027$ & 0.048 \\
Proteinuria & 0.979 & $0.644-1.488$ & 0.922 \\
CVD & 0.901 & $0.623-1.303$ & 0.581 \\
\hline
\end{tabular}

Legend: $B M I$ body mass index, $C K D$ chronic kidney disease, $C V D$ cardiovascular disease, $L D L-C$ low-density lipoprotein cholesterol

cardiovascular morbidity and mortality in patients with diabetes irrespective of their LDL-C levels [7, 9-13]. Whilst the proportion of patients with diabetes who are prescribed statins varies substantially worldwide; there is a low prescribing of statins both in developing and developed countries [18, 19, 21-23, 48-51]. Encouragingly, the percentage of patients with diabetes who received statins (45.5\%) in our study appears appreciably higher than the $3-13 \%$ seen in some African countries and consistent with findings from developed countries where between 25 to $73 \%$ of patients with diabetes are prescribed statins $[18,19,22,48-50]$. The proportion of statin prescription in this population is higher than has been reported in some developed countries, including Germany (25\%) and the United Kingdom (33\%) [18, 48]. While the finding of a comparatively higher statin prescription in this setting than some African countries and some developed countries is encouraging, there is no reason for complacency as more than half of our patients were without CVD protection by statins. Similar to developed countries, one potential explanation for low statin prescribing rates among our patients with diabetes is inadequate adherence to guidelines [22, 51-53]. Whereas there may be a fear of the association of statin therapy with a slightly increased risk of developing diabetes, the benefits of statins in reducing cardiovascular morbidity and mortality among patients with established diabetes should dispel these concerns [7-9, 54]. As mentioned, several epidemiological studies have observed a lower proportion of statin prescribing in patients with diabetes in Africa than in this population [21-23]. In addition to inadequate adherence to guidelines, the main reasons for low statin prescribing in Africa include limited access to these medicines due to their high cost with high copayment levels, inaccessibility to lipid testing facilities and unavailability of guidelines [22]. The presence of free consultations, tests and medications in Botswana might explain our higher statin prescribing rates than those seen in other African settings without universal health access. Irrespective of the reasons, it is imperative that statins are routinely prescribed to reduce the risk of CVD events in patients with type 2 diabetes $[7-13,15$, 55].

Our results of increasing statin prescribing with increasing diabetes duration also agree with previous research findings [56]. This finding is reassuring as a longer duration of diabetes leads to an increased risk of CVD. For this reason, guidelines recommend statins for patients with diabetes for more than ten years [5, 6]. Although the median diabetes duration was seven years in our participants, the association between statin prescribing and diabetes duration was still apparent. The finding may suggest that clinicians correctly recognise a longer duration of diabetes as an indication for statin therapy. As it may take time for the transmission of information between clinicians and patients, the acceptance of new medications is likely easier as the diabetes duration increases [57].

Another finding in our study was that the presence of CKD increased the likelihood of statin prescribing. This finding is also encouraging as statins reduce mortality by up to $36 \%$ in patients with kidney failure $[5,6,58,59]$. The finding is also consistent with SEMDSA guideline recommendations of a statin for every patient with diabetes and CKD [6]. While albuminuria is a marker of renal disease, participants with proteinuria did not receive statin prescriptions. We can postulate that clinicians do not recognise proteinuria as a predictor of CVD and an indication for statins in patients with diabetes. This finding warrants further investigation as it is in contrast with Berthold et al., who reported increased odds of statin prescribing in type 2 diabetes patients with proteinuria in Germany [18].

Our findings that a high baseline LDL-C increased the likelihood of statin prescribing agreed with those of Berthold at al. that showed an $11 \%$ increase in statin prescribing rates for every $0.26 \mathrm{mmol} / \mathrm{L}$ increase in LDLC [18]. This finding also confirms the observation from previous studies that prescribers tend to respond more to the pre-treatment LDL-C value than to the patients' overall CVD risk profile as described in clinical guidelines $[9,52]$. Although there is a lack of local guidelines, our diabetes clinic adopted the SEMDSA guidelines which recommend statins along with lifestyle changes regardless of cholesterol levels for all patients with diabetes aged $>40$ with or without CVD [6]. Our findings that statin prescription was based on LDL-C level may suggest a need for deliberate efforts for improving the understanding and implementation of the adopted guidelines, and we will be taking this further.

In most clinical guidelines, the presence of CVD, $\mathrm{CKD}$, patients age, diabetes and presence of CVD risk 
factors such as hypertension, albuminuria and cigarette smoking are indicators of prescribing statins among patients with type 2 diabetes $[5,6]$. The presence of any of the above factors is associated with an increased risk of CVD. Except for CKD and duration of diabetes, none of the other indications was a predictor of statin prescriptions in this population. Given the high prevalence of hypertension and other indications in this population, most participants would have qualified for statins if guideline recommendations were followed. As our clinic has adopted the SEMDSA guidelines, this finding is a concern and a call for efforts to improve its implementation for the benefit of this high-risk population.

We are aware of a number of limitations of our study. We estimated the baseline LDL-C levels by a $25 \%$ adjustment of measured LDL. There was a risk of either overestimation or underestimation of the baseline LDL-C due to possible errors in our assumptions of the dosage and adherence of atorvastatin. Although measured LDL$C$ results were available for most of the included participants, HDL cholesterol results were mostly missing. Guidelines consider HDL as one of the factors for statin prescribing in patients with diabetes. However, data for all other indications for statin prescribing were available in dataset. We did not document the dosage of statin used in our patients; hence, we are unable to determine whether moderate to high-intensity statins were prescribed as recommended by the guidelines. In addition, we were unable to identify patients with contraindications to warfarin as the information was not available. The study was also performed in one clinic, hence limiting the generalizability of the study findings to other facilities in the country. However, being one of the few specialised diabetes clinics in Botswana, our results likely characterise the 'finest' diabetes care in the country. Consequently, the highlighted concerns are likely to be greater in non-specialist healthcare facilities treating patients with type 2 diabetes in Botswana.

\section{Conclusion}

In conclusion, we believe this study provides a useful and reliable picture of current statin prescribing behaviour in Botswana despite the limitations. There is appreciable under-prescribing of statins in this high-risk population. The presence of CKD, high baseline LDL, and an increased duration of diabetes strongly influenced statin prescriptions in patients with diabetes. Clinicians did not consider most guideline-recommended indications for the prescribing of statins. By identifying gaps in the prescription of statins to patients with diabetes, the study provides an opportunity for improvement in the quality of care. Furthermore, the study findings suggest a need for further studies to investigate the reasons for statin under-prescription in our setting.
We are following this up to provide future guidance for clinicians in Botswana treating patients with type 2 diabetes, with the results likely to be of interest to other sub-Saharan African countries with high rates of type 2 diabetes.

\section{Abbreviations \\ ASCVD: atherosclerotic cardiovascular disease; BMI: Body mass index; CAD: coronary artery disease; CKD: chronic kidney disease; \\ CVD: Cardiovascular disease; eGFR: estimated glomerular filtration rate; HDL- C: HbA1c: Haemoglobin A1c; HDL-C: High-density lipoprotein cholesterol; HRDC: Health Research Development Committee; LDL-C: Low-density lipoprotein cholesterol; MDRD: Modification of Diet in Renal Disease; PAD: peripheral artery disease; SEMDSA: Society for Endocrinology, Metabolism, and Diabetes of South Africa; WHR: Waist-Hip ratio}

\section{Acknowledgements}

This research project has been conducted as part of the academic requirements of the MSc in Clinical Epidemiology www.sun.ac.za/clinepi, Stellenbosch University [60].

\section{Authors' contributions}

JCM, BG and EMT conceptualised the study. JCM analysed data and drafted the initial draft. ETM and BG critically reviewed data and reviewed the manuscripts. All the authors read and approved the final manuscript.

\section{Funding}

No funding was received.

\section{Availability of data and materials}

The datasets used and/or analysed during the current study are available from the corresponding author upon reasonable request and with permission of the HRDC of Botswana Ministry of Health and Wellness.

\section{Ethics approval and consent to participate}

The Health Research Development Committee (HRDC) of the Botswana Ministry of Health and Wellness(HPDME:13/18/1) and Stellenbosch University Health Research Ethics Committee (X19/01/001) approved the current study. The study protocol of the primary study was approved by HRDC and the Princess Marina Research and Ethics Committee. Participating patients provided written, informed consent in the primary study. Authors did not require any administrative permissions to access the data of the primary study.

\section{Consent for publication}

Not applicable.

\section{Competing interests}

The authors declare that they have no competing interests.

\section{Author details \\ 'Department of Internal Medicine, Faculty of Medicine, University of Botswana, Private Bag, 00713 Gaborone, Botswana. ${ }^{2}$ Division of Epidemiology and Biostatistics, Department of Global Health, Faculty of Medicine and Health Sciences, Stellenbosch University, Stellenbosch, South Africa. \\ ${ }^{3}$ Department of Laboratory Medicine, Division of Clinical Pharmacology, Karolinska Institutet, Karolinska University Hospital Huddinge, Stockholm, Sweden. ${ }^{4}$ Strathclyde Institute of Pharmacy and Biomedical Sciences, University of Strathclyde, Glasgow G4 ORE, United Kingdom. ${ }^{5}$ School of Pharmacy, Sefako Makgatho Health Sciences University, Pretoria, South Africa.}

Received: 24 June 2019 Accepted: 27 February 2020

Published online: 10 March 2020

\section{References}

1. Di Angelantonio E, Kaptoge S, Wormser D, Willeit P, Butterworth AS, Bansal N, O'Keeffe LM, Gao P, Wood AM, Burgess S, et al. Association of Cardiometabolic Multimorbidity with Mortality. JAMA. 2015;314(1):52-60. 
2. Huxley R, Barzi F, Woodward M. Excess risk of fatal coronary heart disease associated with diabetes in men and women: meta-analysis of 37 prospective cohort studies. BMJ. 2006;332(7533):73-8.

3. Lloyd-Jones DM, Leip EP, Larson MG, D'Agostino RB, Beiser A, Wilson PW, Wolf PA, Levy D. Prediction of lifetime risk for cardiovascular disease by risk factor burden at 50 years of age. Circulation. 2006;113(6):791-8.

4. Reusch JEDB. Atherosclerosis in diabetes and insulin resistance. Diabetes Obes Metab. 2007;9:455-63.

5. American Diabetes Association. Standards of medical care in diabetes_-2017 abridged for primary care providers. Clinical Diabetes. 2017; 35(1):5-26.

6. SEMDSA Type 2 Diabetes Guidelines Expert Committee. SEMDSA 2017 guidelines for the management of type 2 diabetes mellitus. J Endocr Metab Diabetes S Afr. 2017;22(1 Suppl 1):S1-S196.

7. Colhoun HM, Betteridge DJ, Durrington PN, Hitman GA, Neil HA, Livingstone SJ, Thomason MJ, Mackness MI, Charlton-Menys V, Fuller JH. Primary prevention of cardiovascular disease with atorvastatin in type 2 diabetes in the Collaborative Atorvastatin Diabetes Study (CARDS): a multicentre randomised placebo-controlled trial. Lancet. 2004;364(9435): 685-96.

8. Collins R, Armitage J, Parish S, Sleigh P, Peto R. MRC/BHF Heart Protection Study of cholesterol-lowering with simvastatin in 5963 people with diabetes: a randomised placebo-controlled trial. Lancet. 2003;361(9374): 2005-16.

9. Sever PS, Poulter NR, Dahlof B, Wedel H, Collins R, Beevers G, Caulfield M, Kjeldsen SE, Kristinsson A, McInnes GT, et al. Reduction in cardiovascular events with atorvastatin in 2,532 patients with type 2 diabetes: AngloScandinavian cardiac outcomes trial--lipid-lowering arm (ASCOT-LLA). Diabetes Care. 2005;28(5):1151-7.

10. Baigent C, Blackwell L, Emberson J, Holland LE, Reith C, Bhala N, Peto R, Barnes EH, Keech A, Simes J, et al. Efficacy and safety of more intensive lowering of LDL cholesterol: a meta-analysis of data from 170,000 participants in 26 randomised trials. Lancet. 2010;376(9753):1670-81.

11. de Vries FM, Denig P, Pouwels KB, Postma MJ, Hak E. Primary prevention of major cardiovascular and cerebrovascular events with statins in diabetic patients: a meta-analysis. Drugs. 2012;72(18):2365-73.

12. Hayward RA, Hofer TP, Vijan S. Narrative review: lack of evidence for recommended low-density lipoprotein treatment targets: a solvable problem. Ann Intern Med. 2006;145(7):520-30.

13. Perk J, De Backer G, Gohlke H, Graham I, Reiner Z, Verschuren M, Albus C, Benlian P, Boysen G, Cifkova R, et al. European Guidelines on cardiovascular disease prevention in clinical practice (version 2012). The fifth joint task force of the European Society of Cardiology and Other Societies on cardiovascular disease prevention in clinical practice (constituted by representatives of nine societies and by invited experts). Eur Heart J. 2012; 33(13):1635-701.

14. Perreault S, Dragomir A, Blais L, Berard A, Lalonde L, White M, Pilon D. Impact of better adherence to statin agents in the primary prevention of coronary artery disease. Eur J Clin Pharmacol. 2009:65(10):1013-24.

15. Kearney P, Blackwell L, Ra C, Keech A, Simes J, Peto R, Armitage J, Baigent C. Cholesterol Treatment Trialists'(CTT) Collaborators. Efficacy of cholesterollowering therapy in 18,686 people with diabetes in 14 randomised trials of statins: a meta-analysis. Lancet. 2008;371 (9607):117-25.

16. Eliasson B, Svensson AM, Miftaraj M, Jonasson JM, Eeg-Olofsson K, Sundell KA, Gudbjornsdottir S. Clinical use and effectiveness of lipid lowering therapies in diabetes mellitus--an observational study from the Swedish National Diabetes Register. PLoS One. 2011;6(4):e18744.

17. Balder JW, Scholtens S, de Vries JK, van Schie LM, Boekholdt SM, Hovingh GK, Kamphuisen PW, Kuivenhoven JA. Adherence to guidelines to prevent cardiovascular diseases: the LifeLines cohort study. Neth J Med. 2015;73(7): 316-23.

18. Berthold HK, Gouni-Berthold I, Bohm M, Krone W, Bestehorn KP. Patterns and predictors of statin prescription in patients with type 2 diabetes. Cardiovasc Diabetol. 2009;8:25.

19. Harrison TN, Scott RD, Cheetham TC, Chang S-C, Hsu J-WY, Wei R, Ling Grant DS, Boklage SH, Romo-LeTourneau V, Reynolds K. Trends in statin use 2009-2015 in a large integrated health system: pre- and Post-2013 ACC/AHA guideline on treatment of blood cholesterol. Cardiovasc Drugs Ther. 2018; 32(4):397-404.

20. Simmons RK, Carlsen AH, Griffin SJ, Charles M, Christiansen JS, BorchJohnsen K, Sandbaek A, Lauritzen T. Variation in prescribing of lipid- lowering medication in primary care is associated with incidence of cardiovascular disease and all-cause mortality in people with screendetected diabetes: findings from the ADDITION-Denmark trial. Diabet Med. 2014;31(12):1577-85

21. Gudina EK, Amade ST, Tesfamichael FA, Ram R. Assessment of quality of care given to diabetic patients at Jimma University specialized hospital diabetes follow-up clinic, Jimma, Ethiopia. BMC Endocrine Disord. 2011; 11(1):19.

22. Sobngwi E, Ndour-Mbaye M, Boateng KA, Ramaiya KL, Njenga EW, Diop SN, Mbanya JC, Ohwovoriole AE. Type 2 diabetes control and complications in specialised diabetes care centres of six sub-Saharan African countries: the Diabcare Africa study. Diabetes Res Clin Pract. 2012;95(1):30-6.

23. Uloko AE, Ofoegbu EN, Chinenye S, Fasanmade OA, Fasanmade AA, Ogbera AO, Ogbu OO, Oli JM, Girei BA, Adamu A. Profile of Nigerians with diabetes mellitus - Diabcare Nigeria study group (2008): results of a multicenter study. Indian J Endocrinol Metab. 2012;16(4):558-64.

24. Cameron A, Ewen M, Ross-Degnan D, Ball D, Laing R. Medicine prices, availability, and affordability in 36 developing and middle-income countries: a secondary analysis. Lancet. 2009;373(9659):240-9.

25. Ofori-Asenso R, Agyeman AA. Irrational use of medicines-a summary of key concepts. Pharmacy. 2016;4:35.

26. Kayima J, Wanyenze RK, Katamba A, Leontsini E, Nuwaha F. Hypertension awareness, treatment and control in Africa: a systematic review. BMC Cardiovasc Disord. 2013;13:54.

27. Lloyd-Sherlock P, Beard J, Minicuci N, Ebrahim S, Chatterji S. Hypertension among older adults in low- and middle-income countries: prevalence, awareness and control. Int J Epidemiol. 2014;43(1):116-28.

28. International Diabetes Federation. IDF Diabetes Atlas Brussels: International Diabetes Federation; 2017. 8th edition: Available from: https://diabetesatlas. org/IDF_Diabetes_Atlas_8e_interactive_EN/. Accessed 22 June 2019.

29. Adeniyi OV, Yogeswaran P, Longo-Mbenza B, Ter Goon D. Uncontrolled hypertension and its determinants in patients with concomitant type 2 diabetes mellitus (T2DM) in rural South Africa. PLoS One. 2016;11(3): e0150033.

30. Hamid S, Groot W, Pavlova M. Trends in cardiovascular diseases and associated risks in sub-Saharan Africa: a review of the evidence for Ghana, Nigeria, South Africa, Sudan and Tanzania. The Aging Male. 2019;22(3):169-76.

31. Mwita JC, Mugusi F, Lwakatare J, Chiwanga F. Hypertension control and other cardiovascular risk factors among diabetic patients at Muhimbili National Hospital, Tanzania. East Afr J Public Health. 2012;9(2):70-3.

32. Rannanheimo PK, Tiittanen P, Hartikainen J, Helin-Salmivaara A, Huupponen $R$, Vahtera J, Korhonen MJ. Impact of statin adherence on cardiovascular morbidity and all-cause mortality in the primary prevention of cardiovascular disease: a population-based cohort study in Finland. Value Health. 2015;18(6):896-905.

33. Mwita JC, Magafu M, Omech B, Tsima B, Dewhurst MJ, Goepamang M, Mashalla Y. Undiagnosed and diagnosed diabetes mellitus among hospitalised acute heart failure patients in Botswana. SAGE Open Med. 2017: 5:2050312117731473.

34. Omech B, Mwita JC, Tshikuka JG, Tsima B, Nkomazna O, Amone-P'Olak K. Validity of the Finnish diabetes risk score for detecting undiagnosed type 2 diabetes among general medical outpatients in Botswana. J Diabete Res. 2016;2016:4968350.

35. Mwita JC, Dewhurst MJ, Magafu MG, Goepamang M, Omech B, Majuta KL, Gaenamong M, Palai TB, Mosepele M, Mashalla Y. Presentation and mortality of patients hospitalised with acute heart failure in Botswana. Cardiovasc J Afr. 2017;28(2):112-7.

36. Mwita JC, Francis JM, Omech B, Botsile E, Oyewo A, Mokgwathi M, MolefeBaikai OJ, Godman B, Tshikuka JG. Glycaemic, blood pressure and lowdensity lipoprotein-cholesterol control among patients with diabetes mellitus in a specialised clinic in Botswana: a cross-sectional study. BMJ Open. 2019;9(7):e026807.

37. World Health Organization. Guide to Physical Measurements (Step 2) Geneva: World Health Organization; 2008. Available from https://www.who. int/ncds/surveillance/steps/STEPS_Manual.pdf. Accessed 28 Apr 2019.

38. World Health Organization. Waist circumference and waist-hip ratio: report of a WHO expert consultation, Geneva, 8-11 December 2008. 2011. Available from http://www.who.int/iris/handle/10665/44583. Accessed 28 Apr 2019.

39. Chobanian AV, Bakris GL, Black HR, Cushman WC, Green LA, Izzo JL Jr, Jones DW, Materson BJ, Oparil S, Wright JT Jr, et al. The seventh report of the joint 
National Committee on prevention, detection, evaluation, and treatment of high blood pressure: the JNC 7 report. JAMA. 2003;289(19):2560-72.

40. Friedewald WT, Levy RI, Fredrickson DS. Estimation of the concentration of low-density lipoprotein cholesterol in plasma, without use of the preparative ultracentrifuge. Clin Chem. 1972;18(6):499-502.

41. James PA, Oparil S, Carter BL, Cushman WC, Dennison-Himmelfarb C, Handler J, Lackland DT, LeFevre ML, MacKenzie TD, Ogedegbe O. 2014 evidence-based guideline for the management of high blood pressure in adults: a report from the panel members appointed to the eighth joint National Committee (JNC 8). JAMA. 2014;311(5):507-20.

42. White AD, Folsom AR, Chambless LE, Sharret AR, Yang K, Conwill D, Higgins M, Williams OD, Tyroler HA. Community surveillance of coronary heart disease in the atherosclerosis risk in communities (ARIC) study: methods and initial two years' experience. J Clin Epidemiol. 1996; 49(2):223-33.

43. Levey AS, Greene T, Schluchter MD, Cleary PA, Teschan PE, Lorenz RA, Molitch ME, Mitch WE, Siebert C, Hall PM, et al. Glomerular filtration rate measurements in clinical trials. Modification of diet in renal disease study group and the diabetes control and complications trial research group. J Am Soc Nephrol. 1993;4(5):1159-71.

44. Expert Panel on the Identification Evaluation and Treatment of Overweight in Adults. Clinical guidelines on the identification, evaluation, and treatment of overweight and obesity in adults: executive summary. Am J Clin Nutr. 1998;68(4):899-917.

45. Law MR, Wald NJ, Rudnicka AR. Quantifying effect of statins on low density lipoprotein cholesterol, ischaemic heart disease, and stroke: systematic review and meta-analysis. BMJ. 2003;326(7404):1423.

46. Rwegerera GM. Adherence to anti-diabetic drugs among patients with type 2 diabetes mellitus at Muhimbili National Hospital, Dar Es Salaam, TanzaniaA cross-sectional study. Pan Afr Med J. 2014;17:252.

47. Expert Panel on Detection E, Adults ToHBCi. Executive summary of the third report of the National Cholesterol Education Program (NCEP) expert panel on detection, evaluation, and treatment of high blood cholesterol in adults (adult treatment panel III). JAMA. 2001;285(19):2486-97.

48. Chang KC, Soljak M, Lee JT, Woringer M, Johnston D, Khunti K, Majeed A, Millett C. Coverage of a national cardiovascular risk assessment and management programme (NHS health check): retrospective database study. Prev Med. 2015;78:1-8.

49. Ofori-Asenso R, llomaki J, Tacey M, Zomer E, Curtis AJ, Bell JS, Zoungas S, Liew D. Patterns of statin use and long-term adherence and persistence among older adults with diabetes. J Diabete. 2018;10(9):699-707.

50. Steen DL, Khan I, Becker L, Foody JM, Gorcyca K, Sanchez RJ, Giugliano RP. Patterns and predictors of lipid-lowering therapy in patients with atherosclerotic cardiovascular disease and/or diabetes mellitus in 2014: insights from a large US managed-care population. Clin Cardiol. 2017;40(3): 155-62.

51. Lemstra MBD, Crawley A, Fung R. Proportion and risk indicators of nonadherence to statin therapy: a meta-analysis. Can J Cardiol. 2012;28(5):574-80.

52. Barham AH, Goff DC Jr, Chen H, Balasubramanyam A, Rosenberger $E$, Bonds DE, Bertoni AG. Appropriateness of cholesterol management in primary care by sex and level of cardiovascular risk. Prev Cardiol. 2009; 12(2):95-101.

53. Bai JW, Boulet G, Halpern EM, Lovblom LE, Eldelekli D, Keenan HA, Brent M, Paul N, Bril V, Cherney DZI, et al. Cardiovascular disease guideline adherence and self-reported statin use in longstanding type 1 diabetes: results from the Canadian study of longevity in diabetes cohort. Cardiovasc Diabetol. 2016;15:14.

54. Sattar N, Preiss D, Murray HM, Welsh P, Buckley BM, de Craen AJ, Seshasai SR, McMurray JJ, Freeman DJ, Jukema JW, et al. Statins and risk of incident diabetes: a collaborative meta-analysis of randomised statin trials. Lancet. 2010;375(9716):735-42.

55. Godman B, Shrank W, Andersen M, Berg C, Bishop I, Burkhardt T, Garuoliene K, Herholz H, Joppi R, Kalaba M, et al. Policies to enhance prescribing efficiency in europe: findings and future implications. Front Pharmacol. 2010;1:141.

56. Casagrande SS, Aviles-Santa L, Corsino L, Daviglus ML, Gallo LC, Espinoza Giacinto RA, Llabre MM, Reina SA, Savage PJ, Schneiderman N, et al. Hemoglobin A1C, blood pressure, and LDL-cholesterol control among HISPANIC/LATINO adults with diabetes: results from the HISPANIC COMMUNITY health study/study of LATINOS (HCHS/sol). Endocr Pract. 2017: 23(10):1232-53.
57. Tarn DM, Paterniti DA, Kravitz RL, Heritage J, Liu H, Kim S, Wenger NS. How much time does it take to prescribe a new medication? Patient Educ Couns. 2008;72(2):311-9.

58. Seliger SL, Weiss NS, Gillen DL, Kestenbaum B, Ball A, Sherrard DJ, StehmanBreen CO. HMG-CoA reductase inhibitors are associated with reduced mortality in ESRD patients. Kidney Int. 2002;61 (1):297-304.

59. Tonelli M, Keech A, Shepherd J, Sacks F, Tonkin A, Packard C, Pfeffer M, Simes J, Isles C, Furberg C, et al. Effect of pravastatin in people with diabetes and chronic kidney disease. J Am Soc Nephrol. 2005;16(12):374854.

60. Mwita JC. Statin prescription among patients with type 2 diabetes at a specialised diabetes clinic. Botswana: Stellenbosch University; 2019. Available from: https://scholar.sun.ac.za/handle/10019.1/106905. Accessed 19 Dec 2019 .

\section{Publisher's Note}

Springer Nature remains neutral with regard to jurisdictional claims in published maps and institutional affiliations.
Ready to submit your research? Choose BMC and benefit from:

- fast, convenient online submission

- thorough peer review by experienced researchers in your field

- rapid publication on acceptance

- support for research data, including large and complex data types

- gold Open Access which fosters wider collaboration and increased citations

- maximum visibility for your research: over $100 \mathrm{M}$ website views per year

At BMC, research is always in progress.

Learn more biomedcentral.com/submissions 